US Army Corps of Engineers ${ }_{\circledast}$ Engineer Research and Development Center

\title{
Data Documentation Tool (DDoT) User Manual
}

LaKenya Walker, Joshua Church, and Amy Bednar

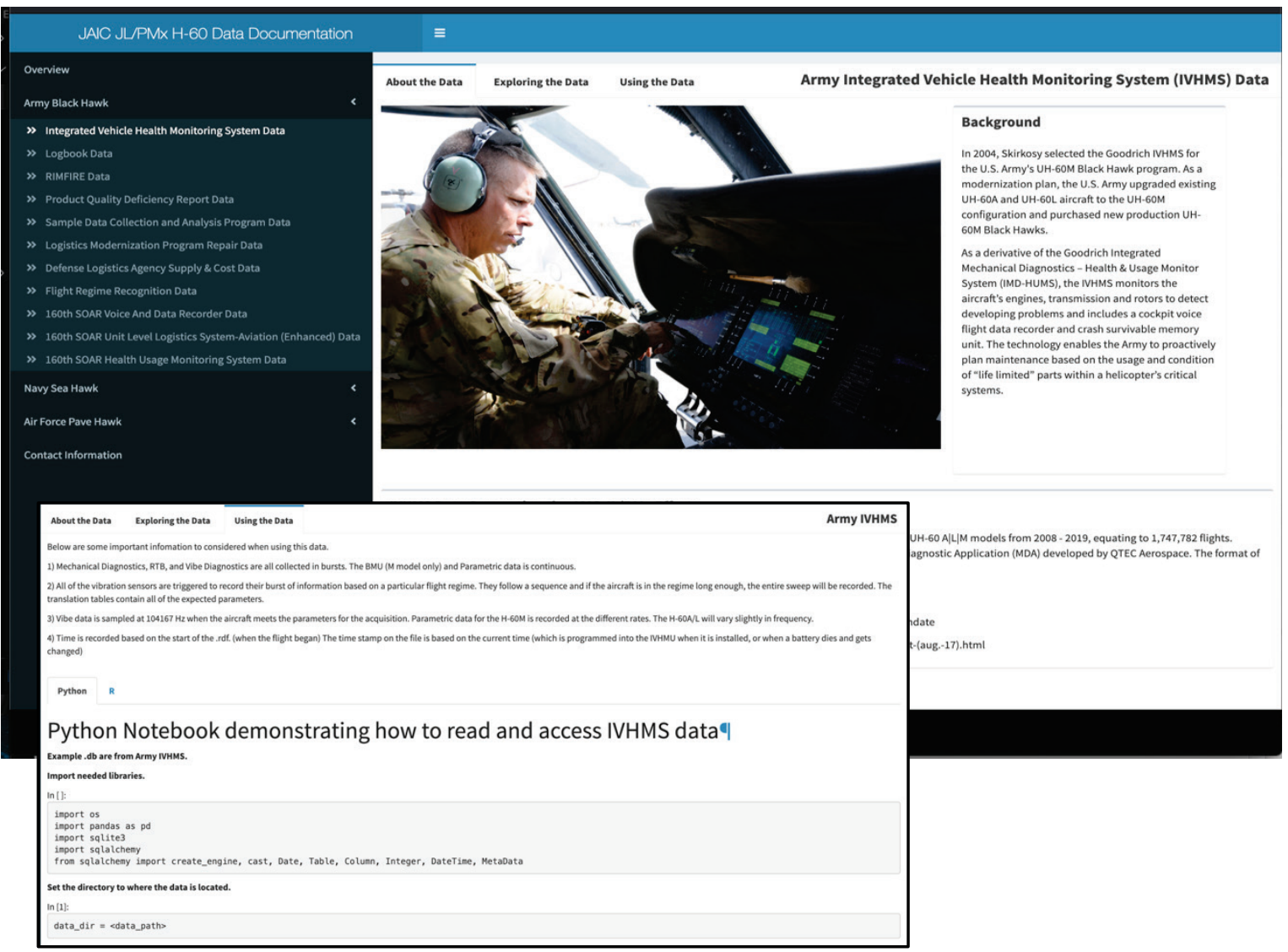

Approved for public release; distribution is unlimited. 
The U.S. Army Engineer Research and Development Center (ERDC) solves the nation's toughest engineering and environmental challenges. ERDC develops innovative solutions in civil and military engineering, geospatial sciences, water resources, and environmental sciences for the Army, the Department of Defense, civilian agencies, and our nation's public good. Find out more at www.erdc.usace.army.mil.

To search for other technical reports published by ERDC, visit the ERDC online library at https://erdclibrary.on.worldcat.org/discovery. 


\section{Data Documentation Tool (DDoT) User Manual}

LaKenya Walker, Joshua Church, and Dr. Amy Bednar

Information Technology Laboratory

US Army Engineer Research and Development Center

3909 Halls Ferry Road

Vicksburg, MS 39180-6199

Final Report

Approved for public release; distribution is unlimited.

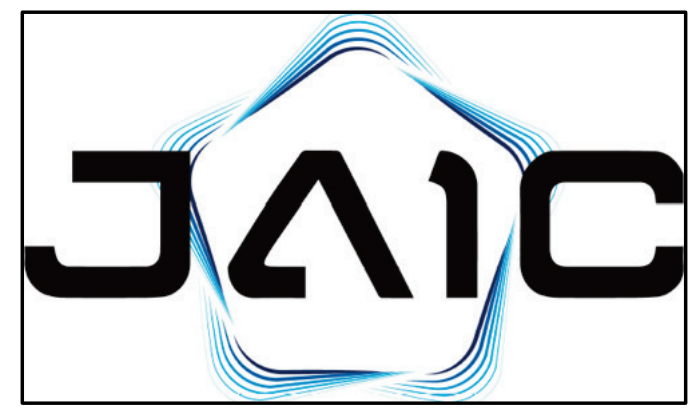

Prepared for Joint Artificial Intelligence Center

Fort Meade, MD 20755

Under MIPR HC1085015834 


\section{Abstract}

This manual is intended for new users with minimal or no experience with using the Data Documentation Tool. The goal of this document is to give an overview of the main functions of DDoT. The primary focus of this document is to demonstrate functionality.

Every effort has been made to ensure this document is an accurate representation of the functionality of the DDoT. For additional information about this manual, contact ERDC.JAIC@erdc.dren.mil.

DISCLAIMER: The contents of this report are not to be used for advertising, publication, or promotional purposes. Citation of trade names does not constitute an official endorsement or approval of the use of such commercial products. All product names and trademarks cited are the property of their respective owners. The findings of this report are not to be construed as an official Department of the Army position unless so designated by other authorized documents.

DESTROY THIS REPORT WHEN NO LONGER NEEDED. DO NOT RETURN IT TO THE ORIGINATOR. 


\section{Contents}

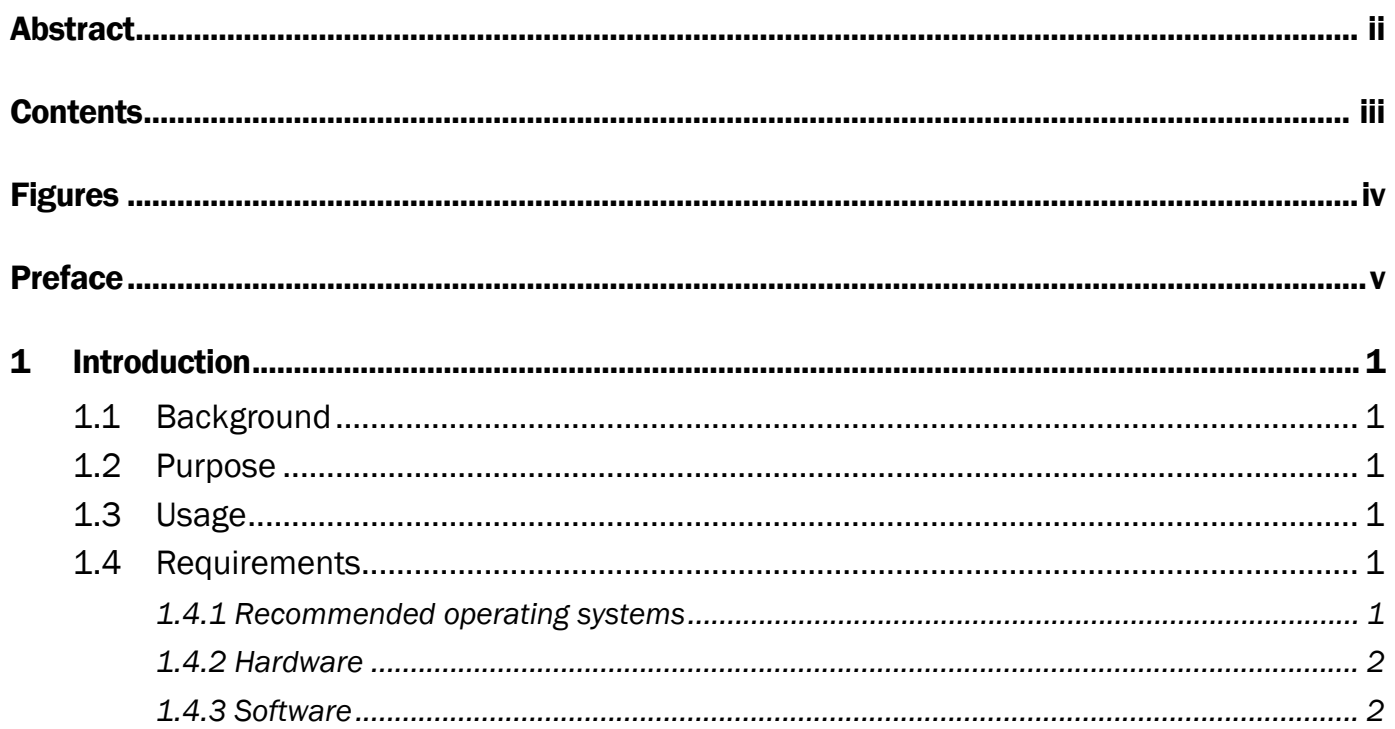

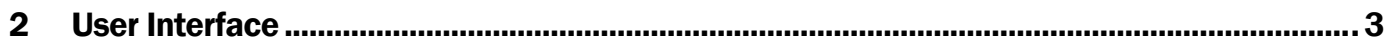

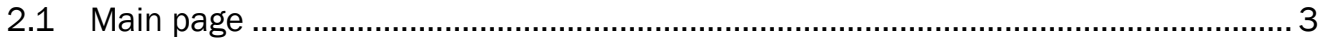

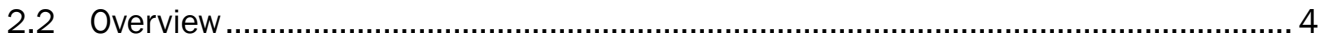

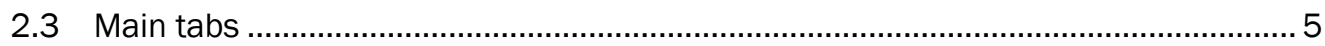

2.4 Army Black Hawk, Navy Seahawk, and Air Force Pave Hawk .................................... 6

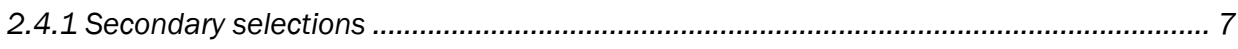

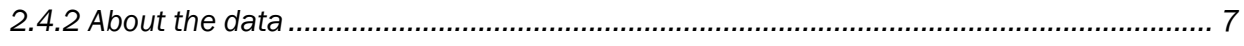

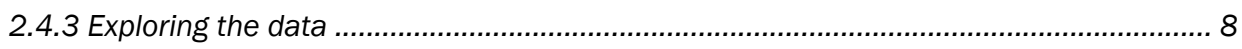

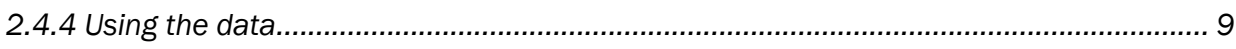

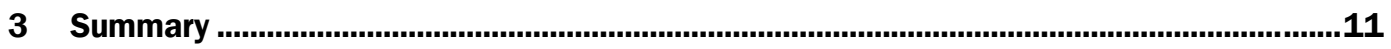

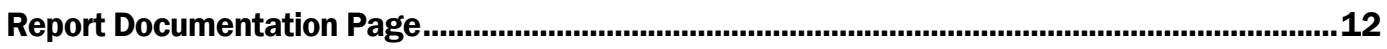




\section{Figures}

\begin{tabular}{|c|c|}
\hline 2 & irst prompt.. \\
\hline 3 & econd prompt. \\
\hline 4 & Overview tab. \\
\hline 5 & Drop down menu button... \\
\hline 6 & Version footer....... \\
\hline 7 & Main tab selection........... \\
\hline 8 & Army Black Hawk tab selection window............. \\
\hline 9 & Navy Seahawk tab selection window............. \\
\hline 10 & 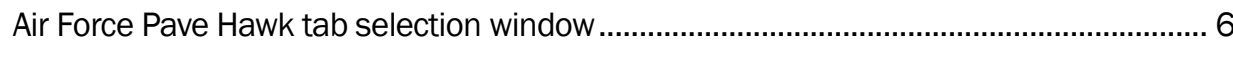 \\
\hline 11 & Informational tab options ........................ \\
\hline 12 & Army IVHMS dataset page ................................... \\
\hline 13 & Army IVHMS-About the Data tab ................... \\
\hline 14 & Army IVHMS-Exploring the Data tab.............. \\
\hline 15 & Army IVHMS tables and descriptions ........ \\
\hline 16 & Army IVHMS fields and descriptions...... \\
\hline 17 & Army IVHMS- Using the Data tab......... \\
\hline & Contact Information tab \\
\hline
\end{tabular}




\section{Preface}

This study was under MIPR HC1085015834 under Project "ERDC PMx Product Transition to the Joint Artificial Intelligence Center (JAIC) Joint Common Foundation (JCF)." The technical monitor was Dr. Maria Niki Goerger.

The work was performed by the Computational Analysis Branch of the Computational Science and Engineering Division, U.S. Army Engineer Research and Development Center, Information Technology Laboratory (ERDC-ITL). At the time of publication, Mr. Joshua Church was Acting Branch Chief; Dr. Jeffrey Hensley was Division Chief; and Dr. Robert Wallace was Technical Director for the Engineered Resilient Systems (ERS) program. The Deputy Director of ERDC-ITL was Dr. Jackie Pettway, and the Director was Dr. David Horner.

COL Teresa A. Schlosser was the Commander of ERDC, and Dr. David W. Pittman was the Director. 


\section{Introduction}

\subsection{Background}

Across the Department of Defense (DoD), there are multiple datasets that support maintenance of the $\mathrm{H}-6 \mathrm{o}$ rotor craft. In an effort to consolidate all the documentation for these datasets into one centralized location, the U.S. Army Engineer Research and Development Center created the Data Documentation Tool (DDoT) to host all the information needed for a user to become familiar with and use these datasets for each service, namely the Army, Air Force and Navy. This application provides the Joint services the capability to explain their datasets without directly communicating with each other. This capability enables ease of access and ultimately reduces the time required to analyze datasets between the Joint services.

\subsection{Purpose}

The DDoT provides users a single, unified, interactive interface for triservice H-6o data documentation, exploration, and usage to support analytics and artificial intelligence model development.

\subsection{Usage}

DDoT is designed to be user-agnostic. Any user that is interested in the cross-service H-6o helicopter data currently supporting the Joint Artificial Intelligence Center (JAIC) Joint Logistics (JL)/Predictive Maintenance (PMx) efforts should find the tool easy to navigate.

\subsection{Requirements}

This section covers the following recommended operating systems and hardware and software requirements for using DDoT.

\subsubsection{Recommended operating systems}

- Windows: Windows 10

- Mac: macOS Sierra or newer

- Linux: Ubuntu. 


\subsubsection{Hardware}

There are no specific hardware requirements for running this tool.

\subsubsection{Software}

DDoT can be executed on any browser that supports R shiny

(https://shiny.rstudio.com/).

Software Needed

- R version 4.0 or greater

- RStudio.

Optional Software Needs

To execute the Python code provided in the tool's Using the Data tabs, a user will need to install Python version 3.0 or greater. 


\section{User Interface}

\subsection{Main page}

Once the DDoT loads (see Figure 1), the user is presented with the following prompt:

Figure 1. Initial screen after opening DDoT.

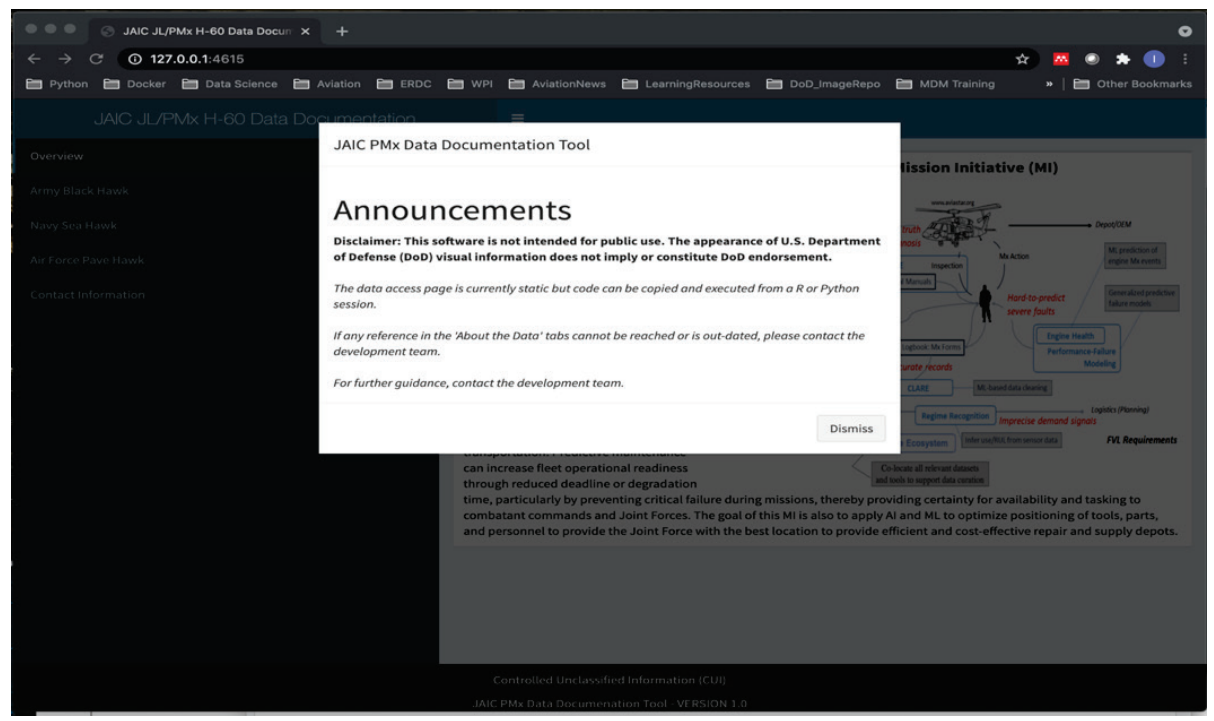

The initial prompt is current information on the DDoT (see Figure 2). The user must click the Dismiss button to proceed to the tool.

Figure 2. First prompt.

\section{JAIC PMx Data Documentation Tool \\ Announcements}

Disclaimer: This software is not intended for public use. The appearance of U.S. Department of Defense (DoD) visual information does not imply or constitute DoD endorsement.

The data access page is currently static but code can be copied and executed from a R or Python session.

If any reference in the 'About the Data' tabs cannot be reached or is out-dated, please contact the development team.

For further guidance, contact the development team.

The second prompt (see Figure 3) provides a Toggle Full Screen button for a better experience of the DDoT. The preference is optional for the user. 
The user must click the Close button on this prompt to go to the main page of the DDoT.

Figure 3. Second prompt.

Attention!

For a better experience, please maximize fullscreen.

Toggle Full Screen

\subsection{Overview}

The Overview tab (see Figure 4) is the starting page after the prompts. This tab contains information on the purpose of the DDoT.

Figure 4. Overview tab.

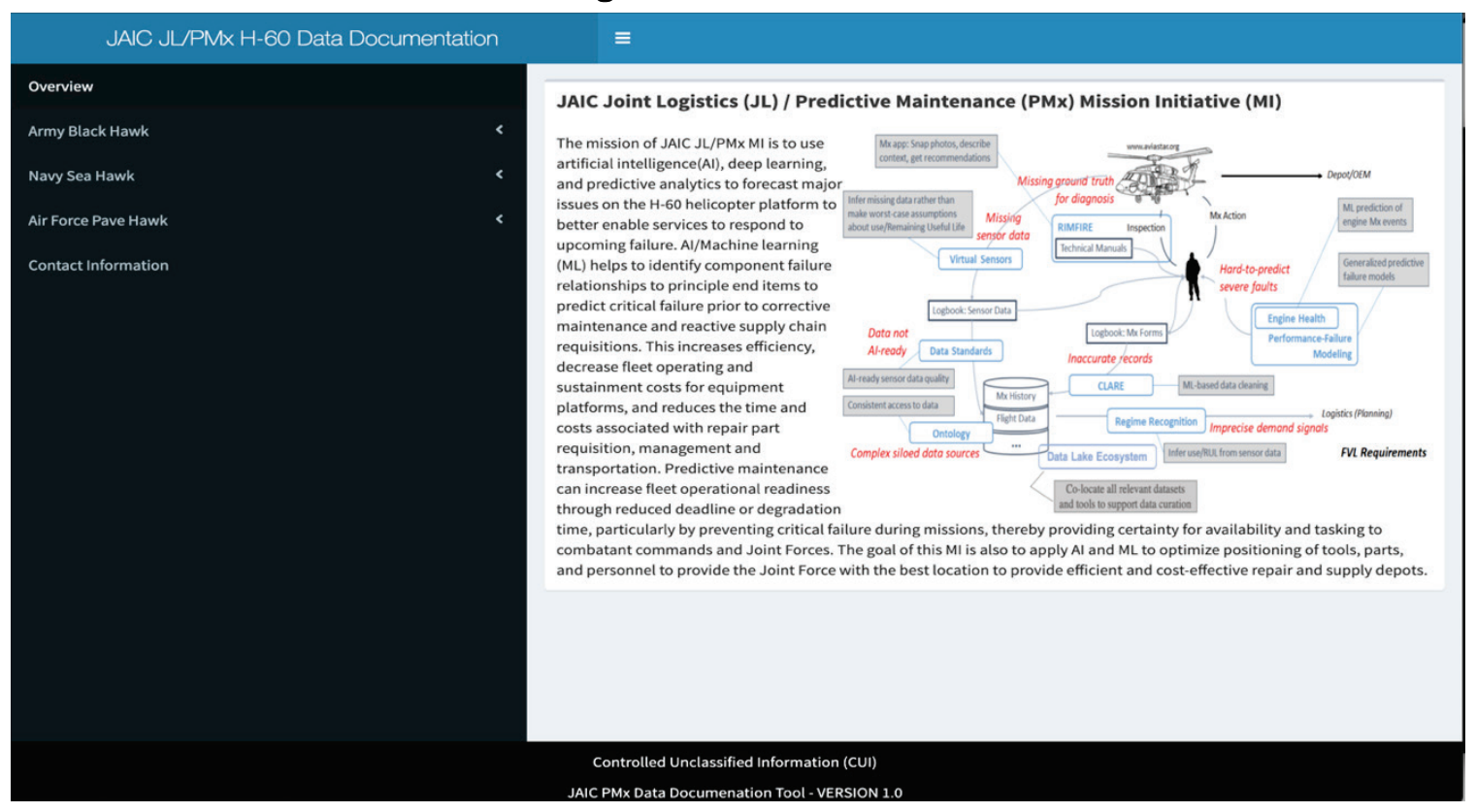

NOTE: When using the DDoT tool, refreshing or closing the browser tab shuts down the application. 
On the left side of the screen, different tab options are available. Information for these tabs can be found under Main Tabs. On the right side of the screen, information based on the selected tab is shown. The three-bar button (see Figure 5) will make the main tabs disappear and reappear.

Figure 5. Drop down menu button.

\section{JAIC JL/PMx H-60 Data Documentation}

The footer as shown in Figure 6 displays the version of the DDoT that the user is using.

Figure 6. Version footer.

$$
\begin{gathered}
\text { Controlled Unclassified Information (CUI) } \\
\text { JAIC PMx Data Documenation Tool - VERSION } 1.0
\end{gathered}
$$

\subsection{Main tabs}

There are six main tab options (see Figure 7) available for the user to select: Overview, Army Black Hawk, Navy Sea Hawk, Air Force Pave Hawk, Joint Forces, and Contact Information.

Figure 7. Main tab selection.

\section{Overview}

Army Black Hawk

Navy Seahawk

Air Force Pave Hawk

Joint Forces 
Information about each tab is located in the following sections.

\subsection{Army Black Hawk, Navy Seahawk, and Air Force Pave Hawk}

Once one of the tabs (Army Black Hawk, Navy Sea Hawk, Air Force Pave Hawk) is selected, there is an additional set of selections as shown in Figure 8, Figure 9, and Figure 10. These selections refer to the current dataset for each branch of service that is in the DDoT. For additional information on this section refer to Section 2.4.1 below.

Figure 8. Army Black Hawk tab selection window.

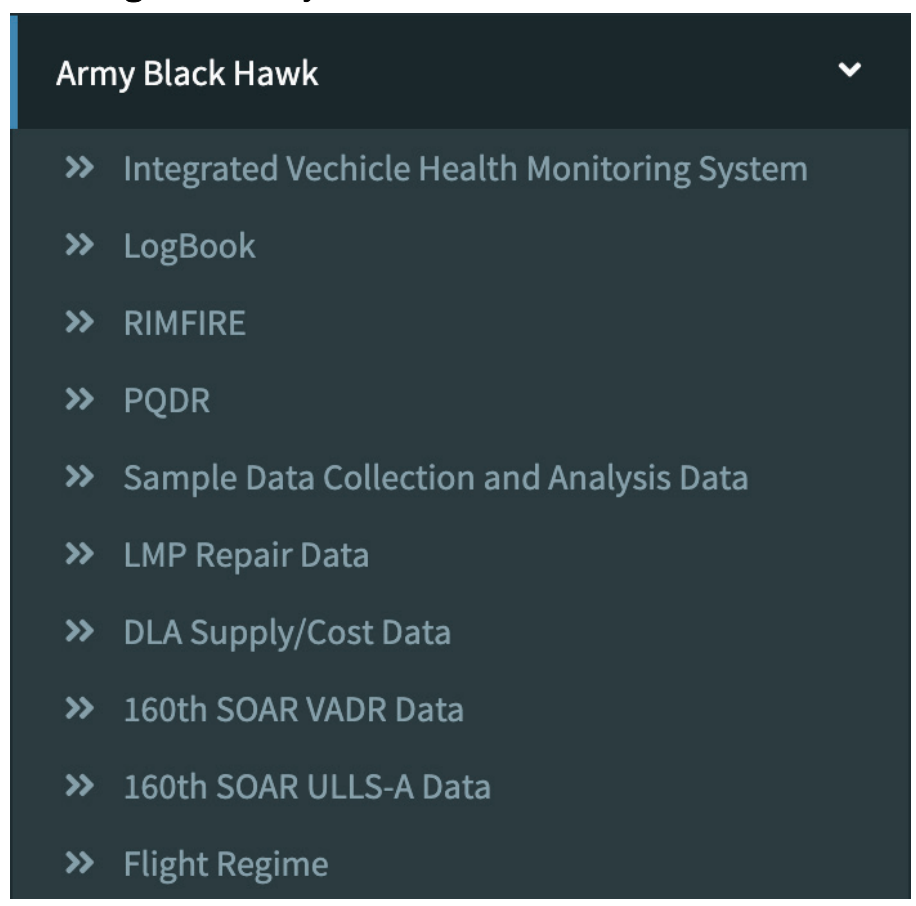

Figure 9. Navy Seahawk tab selection window.

Navy Seahawk

s) Navy LogBook

»N Navy Parametric Data

Figure 10. Air Force Pave Hawk tab selection window.

Air Force Pave Hawk

3) Air Force LogBook 


\subsubsection{Secondary selections}

Once a dataset is selected, three different informational tab options appear as show in Figure 11: About the Data, Exploring the Data, and Using the Data. For example, in Figure 12 the Army Black Hawk Integrated Vehicle Health Monitoring System (IVHMS) dataset tab is selected.

Figure 11. Informational tab options.

About the Data Exploring the Data Using the Data

Army IVHMS

Figure 12. Army IVHMS dataset page.

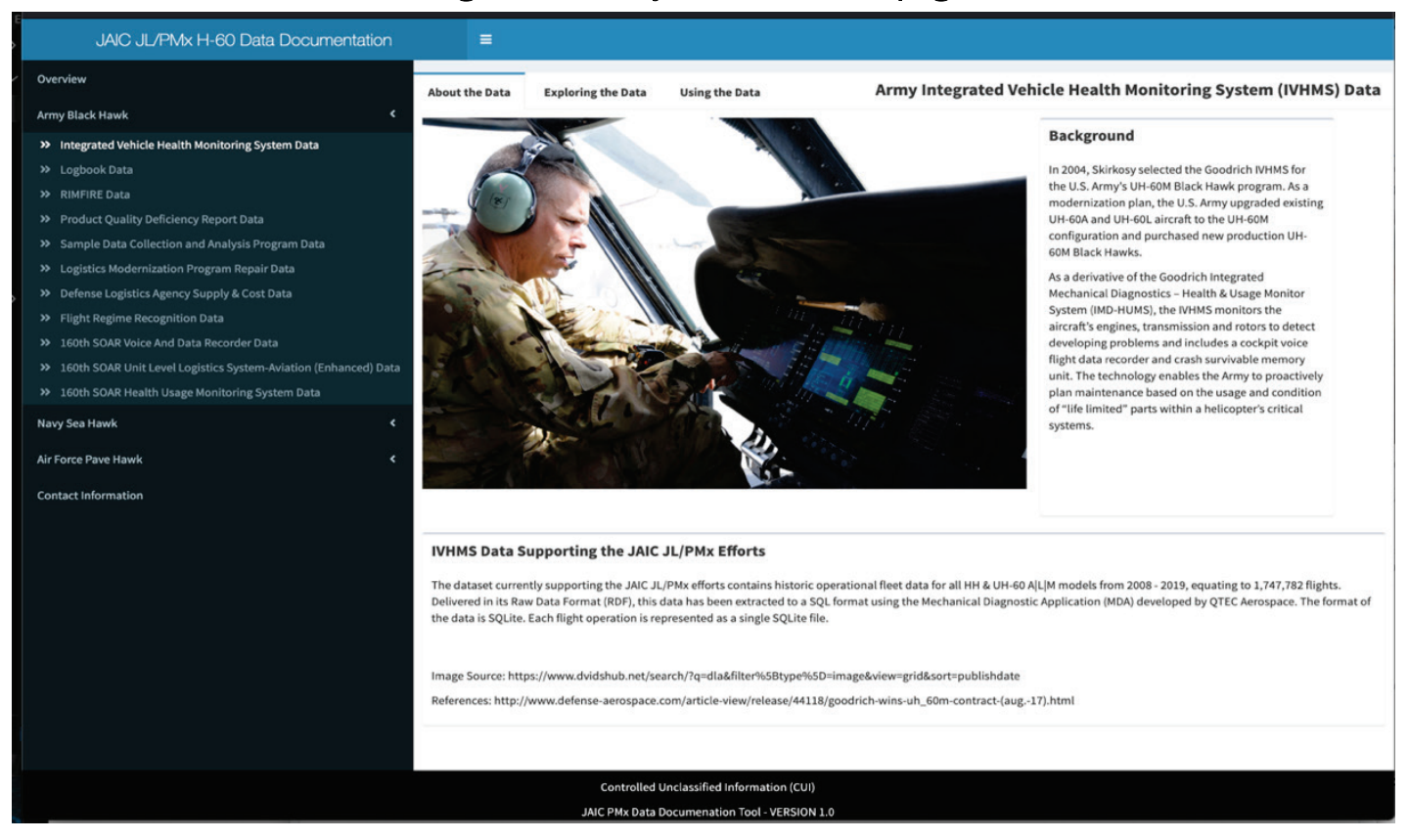

\subsubsection{About the data}

The About the Data tab displays background information on each dataset, such as the source of the data and how the data supports JAIC JL/PMx. For an example, see Figure 13. 
Figure 13. Army IVHMS-About the Data tab.

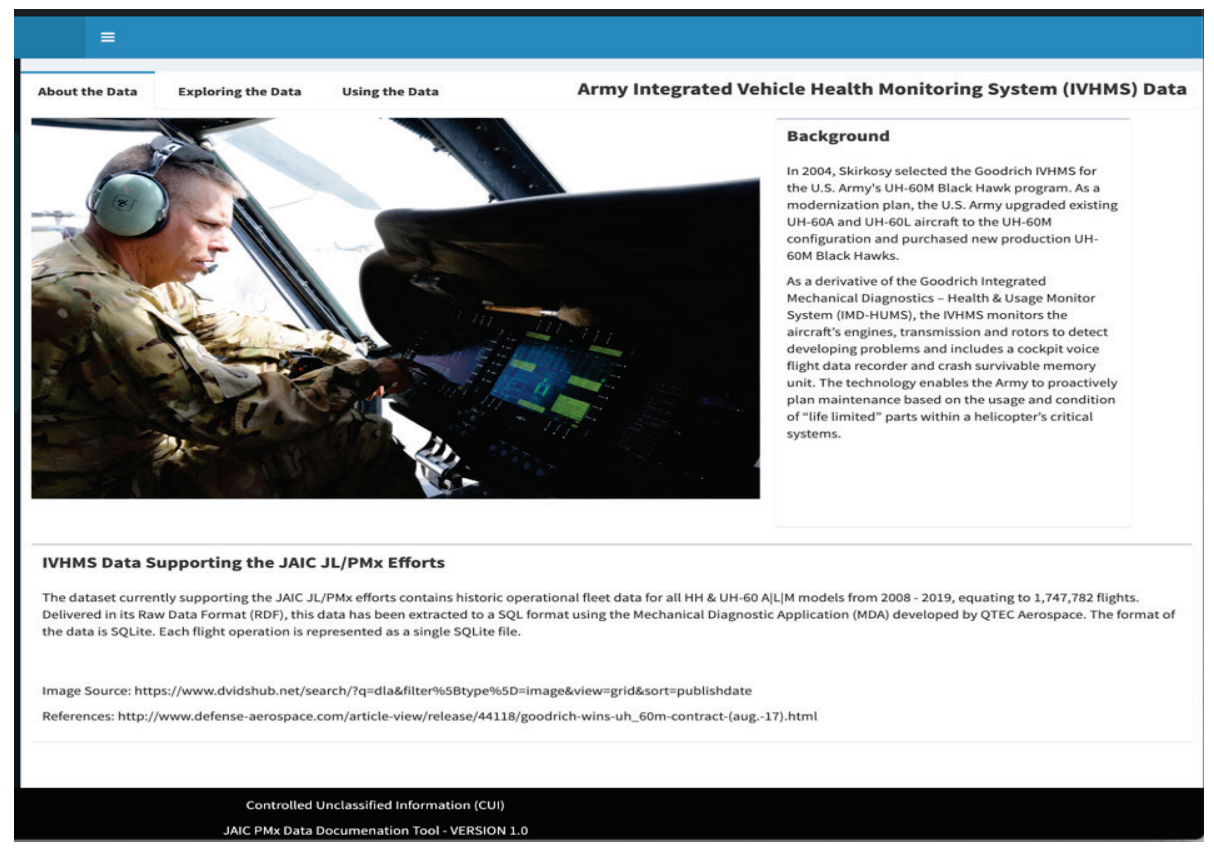

\subsubsection{Exploring the data}

The Exploring the Data tab (see Figure 14) displays information about the number of files in the dataset, dataset size, and dataset format. This page also contains tables and fields related to the selected dataset.

Figure 14. Army IVHMS-Exploring the Data tab.

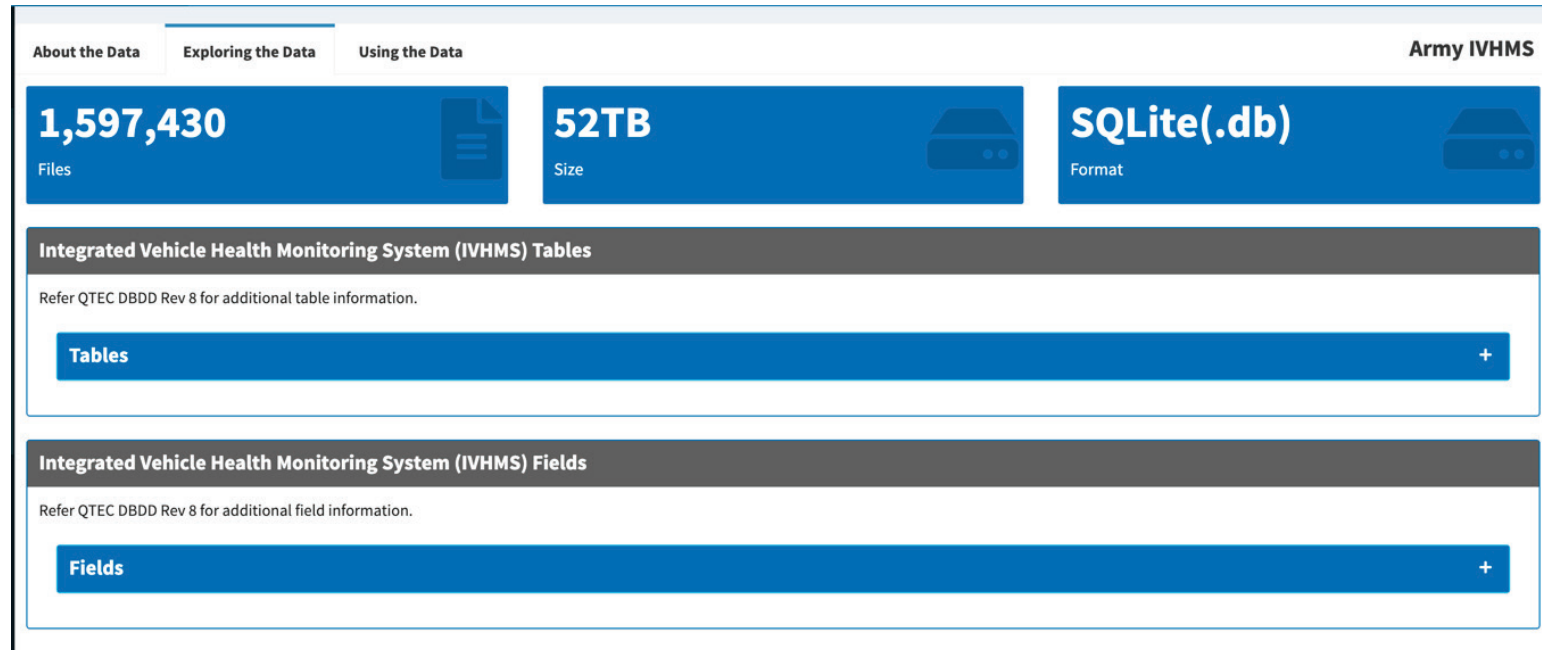

The + or - buttons on the right side of the table expand (+) or minimize (-) the tables and field boxes. For an example, see Figure 15. 
Figure 15. Army IVHMS tables and descriptions.

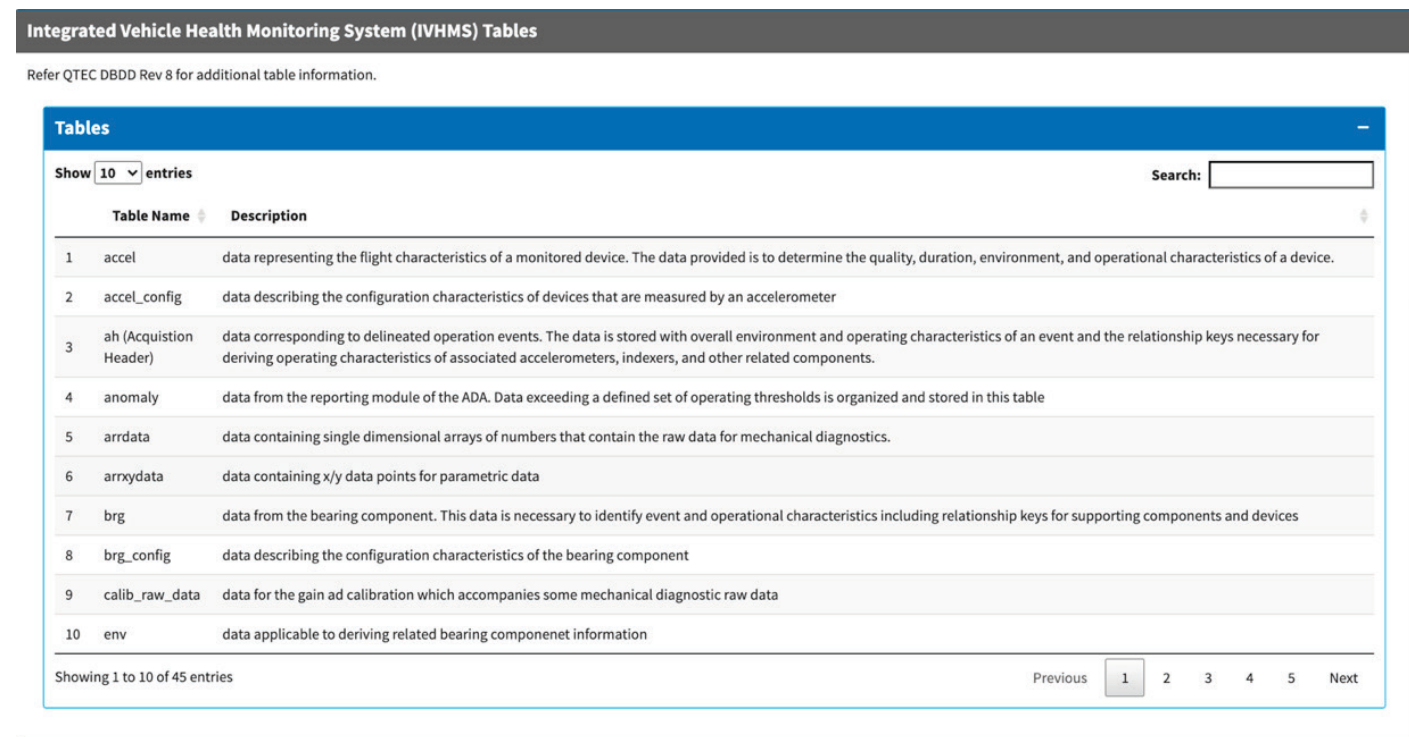

As shown in Figure 16, the user can select which table to display by selecting a table option in the Choose a Table dropdown box. A Search option is available for the tables displayed. The Fields table shows a list of fields and a description for each field.

Figure 16. Army IVHMS fields and descriptions.

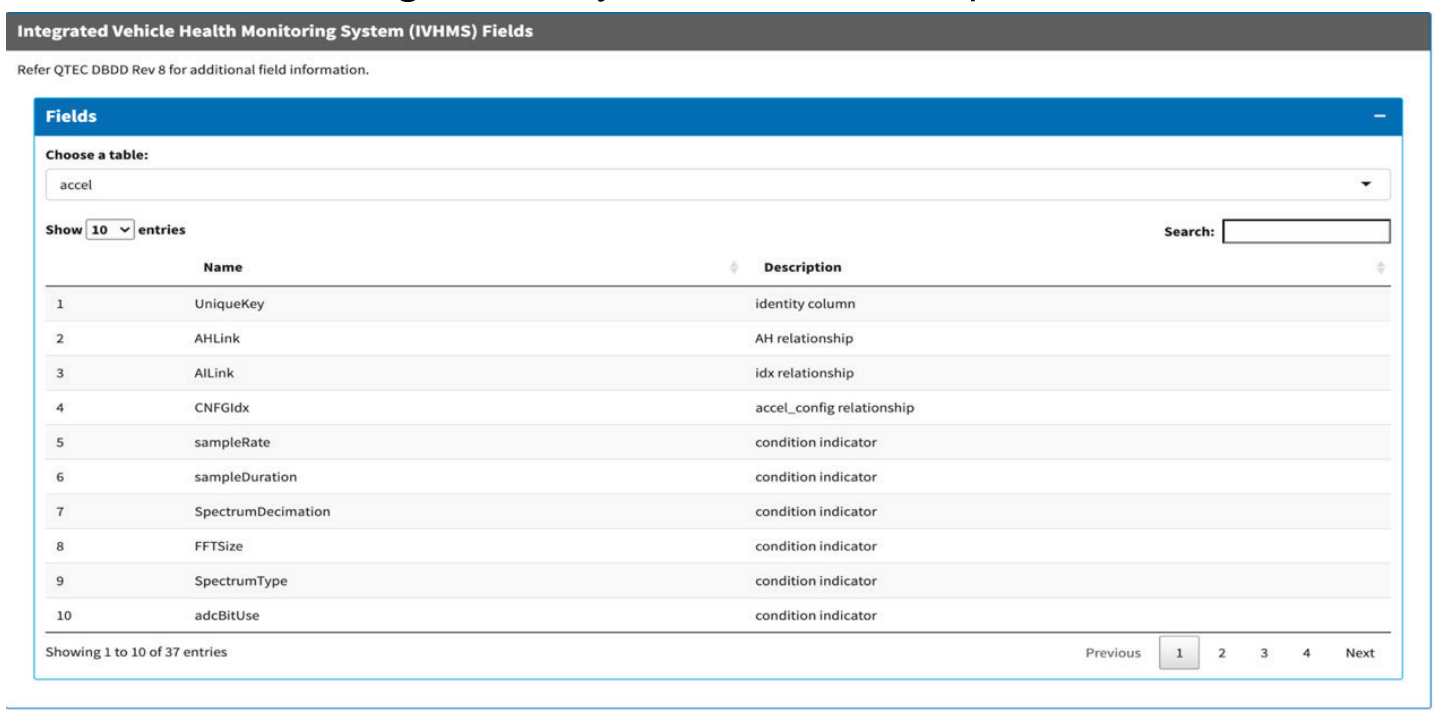

\subsubsection{Using the data}

The Using the Data tab (see Figure 17) displays information about what the user should consider when using the data. The tab will also contain a Python and R script to read and access the selected data. 
Figure 17. Army IVHMS-Using the Data tab.

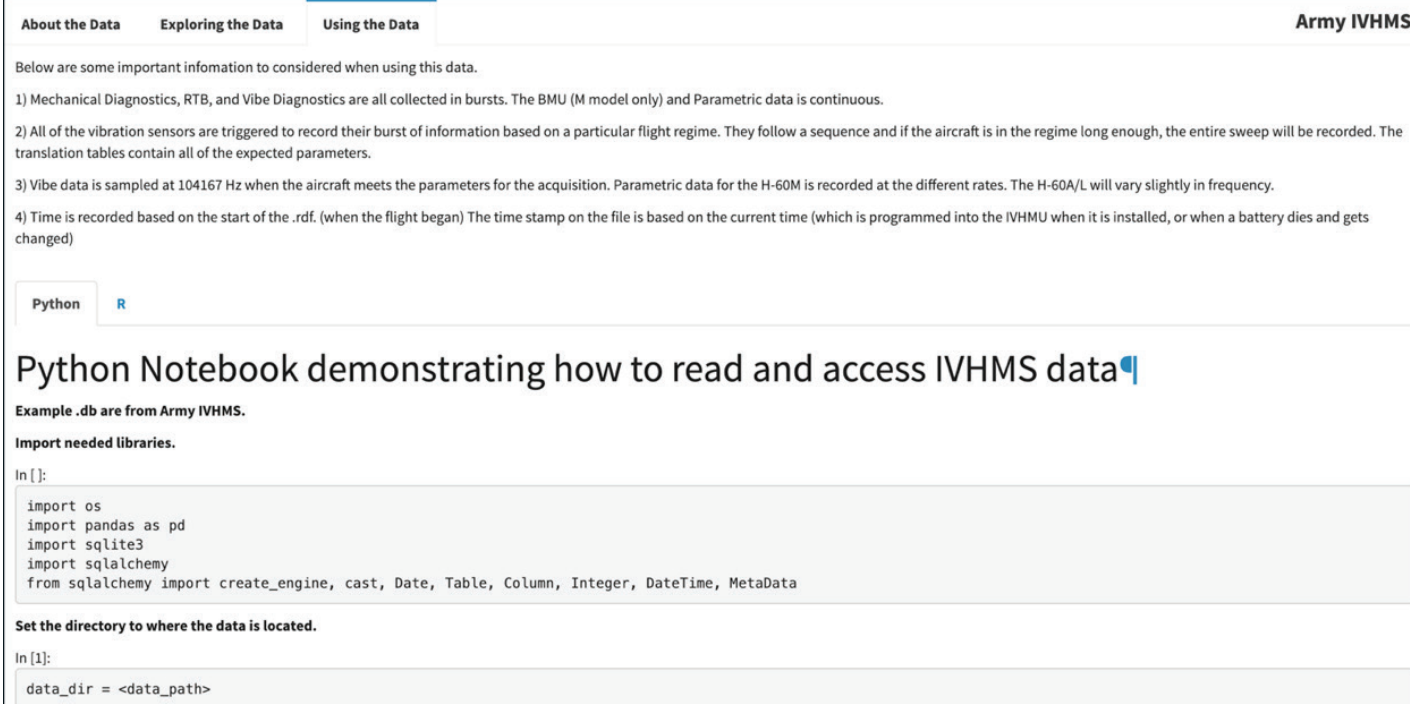

The Contact Information tab (see Figure 18) provides the contact information for the developers of the DDoT tool.

Figure 18. Contact Information tab.

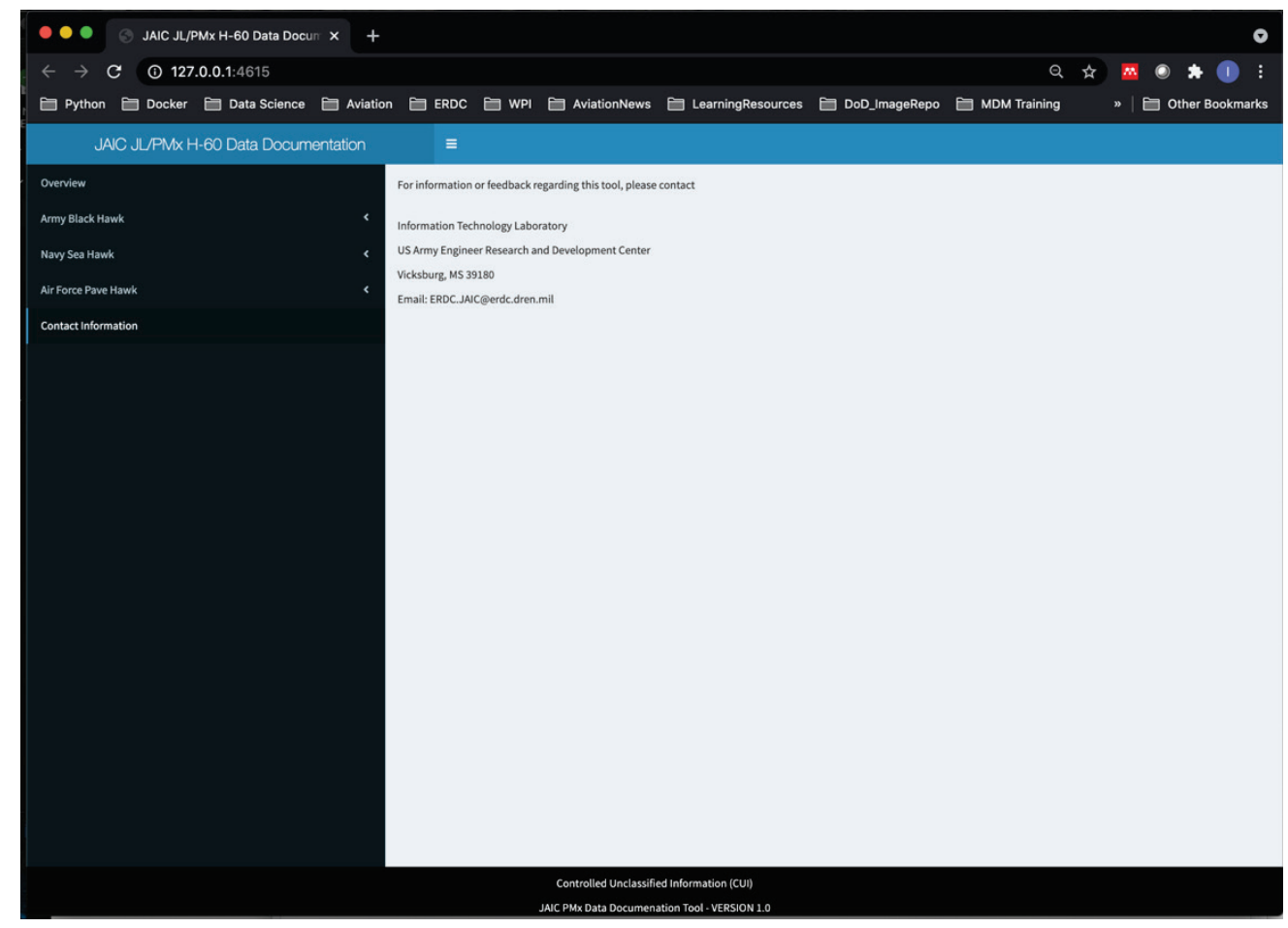




\section{Summary}

DDoT includes a user-friendly graphical user interface (GUI) which provides access to a centralized location to explore the data history, specifications, and documentation for the multiple datasets used to perform vehicle maintenance for helicopters between the Joint services. The ultimate benefit of this tool is that it provides a single, unified, interactive view for data documentation, exploration, and usage for helicopter data. 


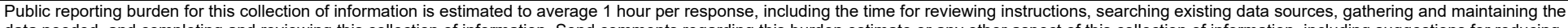

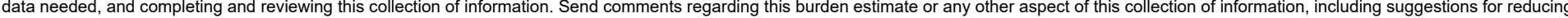

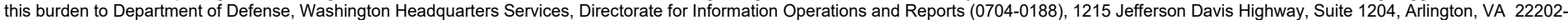

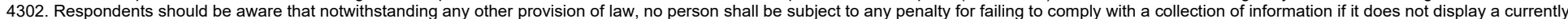
valid OMB control number. PLEASE DO NOT RETURN YOUR FORM TO THE ABOVE ADDRESS

\begin{tabular}{l|l|l} 
1. REPORT DATE (DD-MM-YYYY) & 2. REPORT TYPE
\end{tabular}

4. TITLE AND

August 202 Final Report

Data Documentation Tool (DDoT) User Manual

5a. CONTRACT NUMBER

5b. GRANT NUMBER

5c. PROGRAM ELEMENT

6. AUTHOR(S)

5d. PROJECT NUMBER

LaKenya Walker, Joshua Church, and Dr. Amy Bednar

5e. TASK NUMBER

5f. WORK UNIT NUMBER

7. PERFORMING ORGANIZATION NAME(S) AND ADDRESS(ES)

U.S. Army Engineer Research and Development Center (ERDC)

Information Technology Laboratory (ITL)

Waterways Experiment Station, 3909 Halls Ferry Road

Vicksburg, MS 39180-6199

8. PERFORMING ORGANIZATION REPORT NUMBER

ERDC/ITL SR-21-7

\section{SPONSORING / MONITORING AGENCY NAME(S) AND ADDRESS(ES)}

Joint Artificial Intelligence Center

Defense Information Systems Agency

DISA General Fund Division

6910 Cooper Ave.

Fort Meade, MD 20755

10. SPONSOR/MONITOR'S ACRONYM(S)

JAIC

11. SPONSOR/MONITOR'S REPORT NUMBER(S)

\section{DISTRIBUTION / AVAILABILITY STATEMENT}

Approved for public release; distribution is unlimited.

\section{SUPPLEMENTARY NOTES}

MIPR HC1085015834

\section{ABSTRACT}

This manual is intended for new users with minimal or no experience with using the Data Documentation Tool. The goal of this document is to give an overview of the main functions of DDoT. The primary focus of this document is to demonstrate functionality. Every effort has been made to ensure this document is an accurate representation of the functionality of the DDoT. For additional information about this manual, contact ERDC.JAIC@erdc.dren.mil.

\section{SUBJECT TERMS}

Vehicles, Military-Maintenance and repair-Data sets, Data processing, Computer programs

\section{SECURITY CLASSIFICATION OF:}

a. REPORT

Unclassified

\section{b. ABSTRACT}

Unclassified c. THIS PAGE

Unclassified

\section{LIMITATION} OF ABSTRACT

SAR
18. NUMBER OF PAGES

19 19a. NAME OF RESPONSIBLE PERSON

19b. TELEPHONE NUMBER

(include area code) 